\title{
The representation of sex workers in South African media: Danger, morals and human rights
}

\author{
Sally Hunt and Beatrice Hubbard \\ English Language and Linguistics, Rhodes University, South Africa \\ E-mail: S.Hunt@ru.ac.za
}

\begin{abstract}
The ideological construct of gender typically positions women below men, and "others" certain types of women even more, especially those distinguished from idealised femininity by aspects of their sexuality. This paper explores the representation of sex work and sex workers in the South African media in 2009 and 2010, a time during which there was an increase in news coverage of sex work during the 2010 FIFA World Cup. Analysis of the two data sets revealed that sex work is still often perceived as immoral and dangerous, and that sex workers overwhelmingly represented as women - are criminalised for their actions while client agency is largely obscured, which is in line with previous studies of South African newspapers. However, a strong liberal representation of sex workers was also found in one data set, which advocates the decriminalisation of sex work in the context of human rights. The use of the term "sex work" and its derivatives, rather than "prostitution", was found to index this progressive stance.
\end{abstract}

Keywords: sex work, corpus linguistics, critical discourse analysis, South African media

\section{Introduction}

South African society is arguably more equal today in terms of gender relations than 100 years ago. Nevertheless, sex workers ${ }^{1}$ stigmatised position in society and the skewed demographics within the sex industry - predominantly male clients and female sex workers - are evidence of the continued secondary status of women in society (Weatherall and Priestley 2001, cited in Barrington 2008). Two factors that further contribute to this stigmatised construction are, firstly, that South African law has traditionally criminalised sex workers but not their clients ${ }^{2}$ and, secondly, constant media representations of sex workers as sub-human, diseased, immoral women (Sex Workers Education and Advocacy Taskforce (SWEAT) 2010). The 2011 International Sex Workers' Human Rights Day and the debates around legalising, or at least decriminalising, sex work for the 2010 FIFA World Cup, resulted in increased reporting on sex

\footnotetext{
${ }^{1}$ We use the term "sex work" in this study because it represents the practice as employment motivated by economic reasons (O'Connell Davidson 2002), and it is less stigmatised than "prostitution".

${ }^{2}$ Although Section 11 of the Sexual Offences Act of 2007 allows for the prosecution of clients.
} 
workers in the South African media at the time. We considered this period to be fertile ground in which to look for the beginnings of a change in the way South African media report on sex workers. Of the little research that has been done on the news media's effect on the construction of sex work, all have relied heavily on content analysis, providing weak linguistic evidence for their claims (cf. Barrington 2008, Grjebine 1987, McLaughlin 1991 and SWEAT 2010). This study, using the relatively new combination of critical discourse analysis and corpus linguistics (see, for example, Baker, Gabrielatos, Khosravinik, Krzyzanowski, McEnery and Wodak 2008), explores how the South African news media - specifically, The Sowetan and the Mail and Guardian newspapers - construct sex workers, and what implications these constructions have for South Africa's societal beliefs regarding sex work, gender and sexual intercourse.

\section{The media and social representations}

One of the pivotal sources of shared knowledge, prejudices and ideologies in society is the public discourses created and perpetuated by symbolic elites like journalists (Van Dijk 2005, cited in Baker et al. 2008). News media's social power stems from their control over the selection of news content and emphasis, or lack thereof, and over the extent and frequency of content coverage (Gabrielatos and Baker 2008).

The interaction between producer and interpreter in written communication may be seen as onesided (Fairclough 2001). However, since newspapers have a vested financial interest in discussing issues according to their readership's values and opinions, the relationship between readers and the news media is in fact "bidirectional and dynamic" (Gabrielatos and Baker 2008: 9) through the creation of an ideal reader with whom all writers must negotiate. It follows that an investigation into their readership demographics is potentially very revealing in terms of both the ideologies of the ideal reader as well as the representations we might find in these papers. While our reasons for choosing The Sowetan and the Mail and Guardian in particular will be explained in section 4.2, we limit our discussion here to the demographic profiles of the majority of readers of each publication in order to contextualise the constructions of gender and sex workers under investigation.

\subsection{The Sowetan}

The Sowetan (TS) positions itself as "a fearless advocate of political truth and national development, but also a proud promoter of personal liberation, a champion of lifestyle development, a doyen of enhanced entertainment options and an inspired innovator of information exchange" (Times Media 2014). A noticeable theme in this statement is that of change - positively valued change, at that - with its readers characterised as "in the know and on the move" (Times Media 2014). As such, the data analysed for this study are perhaps better understood in the context of this strongly aspirational vision for the publication.

The average personal income of the 1618000 TS readers in 2010 (AMPS 2012) was R6 969², although only $48 \%$ were employed (Times Media 2014). An overwhelming 94\% speak an African language as their mother tongue (Times Media 2014), with the average age amongst the entire readership being 35 , and $61 \%$ of all readers being between the ages of 25 and 49

\footnotetext{
${ }^{3}$ More than double the median monthly wage of R2 812 in South Africa for 2010 (Statistics South Africa 2010), although the median wage does not necessarily correlate with the notion of 'middle class' in terms of other typical features.
} 
(Times Media 2014). The bulk of the readers are in the Living Standards Measure category of $5-6^{4}$, which correlates with the significantly lower purchase price at just over a quarter of the price of one issue of the Mail \& Guardian.

\subsection{The Mail \& Guardian}

The Mail \& Guardian (M\&G), a weekly South African newspaper, is widely perceived as a liberal publication that often provides a critical perspective on diverse issues in South Africa. The M\&G positions itself as an "intellectual" weekly paper, with a circulation of 428000 in 2012, much smaller than that of TS (AMPS 2012). Throughout its history, the M\&G has maintained that it has no particular political affiliation which it claims is demonstrated by its criticism of all areas of the political spectrum: the M\&G has exposed scandals like the apartheid-era "Inkathagate" scandal and the more recent "Oilgate" scandal (Mail \& Guardian Online 2011a).

The M\&G targets South Africans who are relatively wealthy and highly educated: in addition to the newspaper's use of more formal language, access to the M\&G is further restricted by the publication's high cost. According to the M\&G Online (2011b), at the time of data collection, $14 \%$ of their online users had a household income of over R70 000 a month, 57\% owned property, and $54 \%$ had a university degree. Thus, access to the M\&G's representation of the truth is predominantly restricted to wealthier, well-educated South Africans who own (urban) property. The M\&G Online is restricted due to high internet costs in South Africa, and limited internet access for most South Africans, although internet access in the workplace may make the M\&G Online more accessible to people outside the target market: $58 \%$ of online users accessed the site from work (Mail and Guardian Online 2011b). Most online users are young to middle-aged: $70 \%$ are between the ages of 25 and 54 (Mail and Guardian Online 2011b). The M\&G is likely to structure its articles to suit the perceived ideologies of its predominantly middle-class readership.

\section{The sex industry: News media representations of gender and sexuality}

From a social constructivist feminist perspective, gender is an ideological structure that divides people into two "classes" where men are dominant and women subordinate (Lazar 2005). Beyond this, there is a second hierarchy within the class of women, one that is established through the ideology of an ideal femininity. A cline of powerlessness is thus established amongst women through male societal approval of certain female behaviours over others, thereby producing a spectrum from respectable women, whose behaviours with regard to their gender and sexuality bring approval within patriarchy, and disreputable women, amongst them, sex workers. These dominant views on gender and sexuality are supported by the media's discursive construction of sex workers. In a report produced by SWEAT (2010), an advocacy and education group, sex workers are said to be depicted by the South African print media as transmitters of disease (particularly HIV/AIDS), as shameless criminals, and as sub-human. Underlying these representations is the belief that sex work is deviant and dirty, and that the women in the industry are marginal to the category of "respectable" women, losing power in the process.

Sex work is perceived as deviant in many cultures, and as lying beyond the culturally-defined categories of "normal" sex since it is commercialised, non-monogamous and non-reproductive

\footnotetext{
${ }^{4}$ In 2010, this reflected "some high school" or "high school completed", between $68 \%$ and $75 \%$ cell phone penetration, and a monthly household income averaging between R3 627 and R5 990 (SAARF 2009).
} 
(McLaughlin 1991). In our study, sexuality is not defined as natural or fixed; the apparatus of sexuality, which is socially constructed, categorises sexual behaviour and practices along lines of deviancy (Foucault 1980, cited in McLaughlin 1991). If "natural" and "respectable" women are thought not to share "men's healthy desire for sex" (McLaughlin 1991), then logically one possible reason why some women choose to become sex workers is to satisfy their need for sex, which renders them unworthy of respect. Therefore, according to this view, female sex workers may be seen as unnatural and debauched women who should not be afforded the privileges of normal, respectable women. This presumed peripheral status is taken to legitimise the lack of, and even removal of, basic human rights amongst sex workers.

An examination of the media's discursive construction of sex workers sheds light on what a given society believes about the links between gender, sexuality and sex work since the media both reflect and influence society's values and beliefs. We take a neo-Marxist perspective on ideology, defining it as a body of common-sense assumptions that people unthinkingly draw upon and which justify the actions of those in power (the dominant bloc) by misrepresenting reality (Fairclough 2001). Ideology is seen to be carried by discourse (Sunderland 2004) - the use of language as social action. The "taken-for-grantedness" (Lazar 2005: 7) or "naturalisation" (Fairclough 2001: 76) of dominant discourses, usually achieved through repetition, obfuscates the inherent power differentials and inequalities within these discourses (Lazar 2005), and the mass media play a significant role in (re)producing these repeated discourses. Therefore, discourse regulates gender and sexuality, amongst other things, through commonsensical beliefs and traditions that receive consensus and are accepted by most communities (Lazar 2005), and the discourses favoured by the media are particularly frequently reiterated.

At any given time there are multiple ideologies in circulation, of which only a few will be dominant at any given moment, while others will occupy various positions relative to the powerful worldviews. These include normative ideologies which support the status quo in terms of power relations, resistant ideologies which contest the power relations inherent in the dominant ideology/ideologies, or transformative ideologies which, if they gain traction, can result in a paradigm shift in some aspect of life. This means that there will always be discourses which are rising in terms of the power associated with them and which are possibly en route to becoming a dominant way of seeing the world, and others which are waning in currency. Shifts in society's views on sex work and gender should be reflected in changes in the representations found in the media, tailored as they are to ideas about who the ideal reader is.

Relatively little research has been done on the news media's influences on attitudes towards sex work, despite the wealth of research on the influences of the mass media in general (e.g. McLaughlin 1991; Hallgrimsdottir, Phillips and Benoit 2006; O'Neill, Campbell, Hubbard, Pitcher and Scoular 2008; Coy, Wakeling and Garner 2011). Grjebine (1987) claims that greater media coverage of sex workers' living and working conditions has reduced some of the more serious abuses against them, although it is acknowledged that coverage was sometimes sensationalised. The Scelles Foundation (2009) and SWEAT (2010) both state that sensationalist journalism hinders progress by preventing in-depth analysis of the various causes of sex work or of the individuals involved in the industry. While SWEAT's report (2010) certainly provides a perspective sympathetic to sex workers, noting their persecution by society and the news media, the researchers provide weak linguistic evidence by relying on content analysis. This weakness is also present in Barrington (2008) who relies on a Foucauldian perspective to analyse the news media without the use of any formal linguistic evidence. While 
there have been a number of linguistic studies on the representation of other marginal groups in Europe - such as immigrants (Baker et al. 2008) and the elderly (Mautner 2009), both in the UK - these and other disempowered groups have largely been absent from linguistic study in terms of their representation in the South African media (but see Crymble 2011). Our study aims to address this gap by analysing the discursive construction of sex workers in the press using - as do the studies mentioned above - the combination of critical discourse analysis and corpus linguistics, which teases out solid linguistic evidence from ideologically-rich media representations.

\section{Research methodology}

Using this combination of corpus linguistics (CL) and critical discourse analysis (CDA) to analyse data from two South African national newspapers (TS and the M\&G), this study reveals the ideological representations of sex workers constructed by selected local news media. The news media's reflection of and strong influence on public opinion (Baker 2008) means that this study provides an insight into South Africans' societal beliefs regarding sex work, gender, sexuality and sexual intercourse.

\subsection{Analytical framework: Combining CL and CDA}

CL "utilises a collection of different methods which are related by the fact that they are performed on large collections of electronically stored, naturally occurring texts" (Baker et al. 2008: 274). The use of corpus investigation software organises the items in a corpus so that statistical information about the data can be produced and analysed (McEnery and Wilson 2001). This software also produces concordance data so that researchers can investigate nodes in their co-text (Mautner 2009). Frequently occurring word forms or patterns are particularly significant as they indicate what the text producer and, to an extent, a group or society emphasise and thus value (Baker 2006), while frequently co-occurring items are suggestive of discourse prosodies, i.e. statistically significant collocational relationships in which the evaluative aura of one term colours the meaning of others with which it is often found (Baker 2006). This study uses AntConc 3.2.2, a freeware concordancer that allows analysts to investigate nodes in context (concordances) and produce statistical information including collocations, frequency word lists and keyword lists (Anthony 2011).

CDA is a heterogeneous programme (Wodak and Meyer 2009) that is fundamentally interested in analysing structural relationships of power and control as manifested in language (Baker et al. 2008). Discourse is seen as both socially constitutive, in that it sustains, reproduces and possibly transforms the social status quo, and as socially conditioned by "situations, objects of knowledge, and the social identities of and relationships between people and groups of people" (Fairclough and Wodak 1997: 258, cited in Wodak and Meyer 2009). Power is signalled not only through grammatical forms in the text but also through the text producer's control over the social occasion by manipulating the genre of the text or limiting access to public fora (Baker et al. 2008). While CDA is widely accused of researcher bias, Fairclough (2001) argues that CDA practitioners acknowledge their political standpoint by not presuming to be objective in a social world.

The relatively new combination of CDA and CL has significant benefits for both methodologies (see Baker et al. 2008). Since it considers a text producer's choice of a specific linguistic form over a variety of others - that is, both absences and presences are examined (Kress and Van 
Leeuwen 2001, cited in Baker et al. 2008) - CDA adds a further social dimension to purely descriptive, corpus-driven approaches (Baker et al. 2008). In addition, CL complements CDA in that it reduces researcher bias by broadening the empirical base in comparison to timeconsuming manual analysis (Hardt-Mautner 1995).

We base our investigation on Fairclough's (2001) three levels of analysis: description, interpretation, and explanation, with our description stage coinciding with the CL data analysis. While we acknowledge the need to consider the data in terms of its micro-level features, its immediate context of production and interpretation, and its broader social context, in line with the three levels or stages mentioned above, we have merged these considerations in our data analysis into a single discussion in the interests of clarity and to avoid repetition. CL techniques tend to privilege the lexical aspects of discourse analysis, however this is not in itself problematic, as much of the evaluative force of a text is carried in the choice of words and the way they co-occur. If necessary, there are ways in which more syntactic elements may be investigated, e.g. the use of clusters and regular expressions. On balance, the advantages to be gained from the processing power and statistical analysis of CL far outweigh those elements that are more difficult to access using this technique.

Fairclough's (2001) description stage involves the consideration of three values present in the textual data:

(i) experiential value: the representation of a text producer's experience of social reality and concern with their knowledge and beliefs;

(ii) relational value: the implicit social relations located in the text, and

(iii) expressive value: an important cue to a text producer's evaluation of social reality.

In our study, overwording (high frequency items in the word list generated by AntConc) and classification schemes (often revealed as collocates of the high frequency types, clustered into semantic domains) provide an indication of the text producer's preoccupation with some aspect of reality, as well as the text producers' attitudes towards these representations, seen as the positive or negative expressive value in the texts.

We chiefly used four corpus processes to uncover the experiential and expressive values in the corpora: frequency, collocations, concordances, and keywords. Firstly, a word list was generated of the most frequent types in each corpus. High frequency content words indicate what semantic domains are particularly salient in the corpus. In our corpora, for example, the token sex was very high on both frequency lists, which was expected given that this was one of the search terms used to collect the data. However, a stronger statistical measure of saliency is keyword lists, which relates specifically to working with two corpora. A word is key if it occurs significantly more frequently when compared to a reference corpus; hence, keywords can be indicators of the "aboutness" and style of a particular corpus (Sinclair 2006). AntConc uses the frequency lists of two corpora to measure the most significant lexical differences between the two corpora using a computational formula (in this study, Log Likelihood). Like frequency, keywords do not reveal discourses but rather direct us towards "important concepts in a text (in relation to other texts) that may help to highlight the existence of (embedded) discourse or ideology" (Baker 2004: 347) through an examination of collocations and concordance lines. 
A collocation is "the above-chance frequent co-occurrence of two words within a predetermined span, usually five words on either side of the word under investigation" (Baker et al. 2008: 278). Collocations are particularly useful in the initial stages of analysis because they highlight the most obvious lexical patterns surrounding a subject from which discourses can be derived (Baker 2006). Our spans for collocation varied according to research needs, but the default setting was four tokens to the left and right $(4 \mathrm{~L}-4 \mathrm{R})$. We used the Mutual Information (MI) score provided by AntConc because it favours low frequency words (Baker 2006), which is useful for investigating less frequent content words in smaller corpora such as ours. MI scores over 3 are deemed statistically significant and indicate a real link between the search term and its collocates in that their meanings are mutually affected and the construction of discourses may become evident ${ }^{5}$.

Nevertheless, collocations can have fairly low statistical scores, especially in small corpora, so a more qualitative aspect - concordances - was used in tandem. A concordance or KWIC (key-wordin-context) sort provides examples of a chosen word or cluster of words in their immediate co-text ${ }^{6}$, thereby producing the context that CDA practitioners value so highly (Baker et al. 2008). Sorting the concordance in different ways helped us to pick out repeated patterns of language use. These repeated patterns can reveal semantic prosodies at the level of a word, that is, a word is primed for a particular meaning or usage according to the company it keeps (Baker 2006). The evaluative meanings encoded in these semantic prosodies are ideologically interesting, and can reveal evaluative patterning at a discoursal level rather than simply at the lower level of the word (i.e. discourse prosodies). In some cases, the frequency of each association is relatively low, but they cluster into semantic groups or themes which suggest particular views of the profession, and these are discernable in thematically-sorted concordance lines.

Finally, the patterns and tendencies identified in the data were interpreted in terms of the relationship between the text and interaction processes, and in the broader social and theoretical context, to examine the power relations that shape discourse, the ideologies that underlie discourse, and the social effects of discourse (Fairclough 2001). In this way, we aim to show how linguistic features identified in the data reveal systematic representations which themselves build into discourses about sex work which, when reiterated by the symbolic elites of the press, function to do ideological work on an individual and social level.

\subsection{The corpora}

As previously mentioned, we chose two South African newspapers to create the two corpora for this study: The Sowetan (TS) and the Mail \& Guardian (M\&G). We chose these particular publications so as to achieve a spread in terms of readership and general perceived orientation; in international terms, the two papers could be classified as tabloid and broadsheet, respectively. Naturally, including data from more national newspapers would have enhanced the study, but the current sample is not unrepresentative of the market and offers a potentially interesting contrast.

\footnotetext{
${ }^{5}$ Indeed, had this study been carried out using a large general corpus, as opposed to a small specialised one, these scores would undoubtedly have been higher, as many of the collocates identified are naturally more frequent in our corpora, given the way in which the data were selected, than they would be in general media texts. This means that the frequency of the collocates within the specified span is not as different as it would be when compared with a general corpus.

${ }^{6}$ As is conventional in CL research, the concordance lines used for exemplification below are given with their cotext on either side, centred in italics. For neat formatting, the co-text may have been reduced in length.
} 
The data comprise all the edited articles published between January 2009 and March 2011 from TS and the M\&G that had sex work as the main topic. Due to the discussions surrounding the 2010 FIFA World Cup and the 2011 International Sex Workers' Human Rights Day, there was increased reporting on sex workers, making this time period ideal for specialised corpus construction. It also fell after the period during which SWEAT collected the media texts they analysed, allowing for a certain amount of comparison in terms of dominant themes in representation. Using the search terms sex work* and prostitut*, Lexis Nexis yielded a TS corpus of 15468 words from 43 articles, after cleaning ${ }^{7}$, and a M\&G corpus of 10984 words from 16 articles. Although these are relatively small corpora and would not really be sufficient for corpusbased variationist studies, for instance, given the specialised nature of the data, we consider it ample to reveal trends in terms of ideological orientation, as Baker (2006) did in his study of holiday brochures where his corpus comprised only 17865 running words. The difference in average article length between our two publications is interesting, suggesting scope for more indepth coverage in the $M \& G$ than TS.

Table 1: M\&G and TS data: articles with sex work* and/or prostitut* - January 2009 to March 2011

\begin{tabular}{|l|l|l|}
\hline & TS & MG \\
\hline Articles with prostitut $^{*}$ & 68 & 44 \\
\hline Articles with sex work $^{*}$ & 23 & 28 \\
\hline $\begin{array}{l}\text { Total articles remaining after } \\
\text { cleaning }\end{array}$ & 43 & 16 \\
\hline Total words & $\mathbf{1 5 4 6 8}$ & $\mathbf{1 0 ~ 9 8 4}$ \\
\hline
\end{tabular}

\section{Findings: Constructions of sex work}

In this section, we report on our analysis of the two corpora involved in this study. Rather than focusing on each corpus in turn, we have arranged our findings according to the constructions of sex work evident in the entire data set, pointing out similarities and differences between the two publications where appropriate. Cutting across these trends are patterns in the representation of sex workers themselves, sometimes as individuals and other times as a group, with the two corpora showing preferences here as well.

The clearest standpoint in the M\&G data is the unequivocal condemnation of human rights abuses. The $M \& G$ data set, however, did not reflect one set of discourses but rather a more nuanced and at times oppositional complex of views, spanning both sides of the feminist debate on sex work (i.e. sex work as exploitation versus sex work as emancipation - see O'Connell Davidson 2002). In some articles, sex work was portrayed as a form of male exploitation of a sexualised (female) body, while in others, sex work was portrayed as a form of employment where women have control over their sexuality. Both these stances tended to be fairly abstract and theoretical; other voices which were more religious, emotional or "cultural" were generally marked as different. However, the pro-decriminalisation stance evident in most of the M\&G data is reflected in the almost exclusive use of the terms derived from sex work* as opposed to those from prostitut*.

\footnotetext{
${ }^{7}$ Cleaning involved removing duplicate articles and irrelevant articles from both corpora, and metadata from the articles themselves.
} 
The representation of sex work and sex workers in the TS corpus is much more mixed, as the following analysis will show. There is no single voice which dominates the data; instead, a multiplicity of views is evident, ranging from a view of sex work as social deviance associated with crime, to a more liberal, advocacy stance. The choice of term to refer to sex work clearly indexes which ideological position is being taken, with sex work* aligning more with the drive to decriminalise the industry, and prostitut* with rather more conservative views. Overall, the preference for one set of terms is very clear in each article and forms a strong indicator of the overarching discourse which is supported by that article. However, the multiplicity of views on sex work does not mean that this corpus is characterised by articles which each display balance internally; rather, they form an assemblage of texts, each with one view of sex work, which together span quite a range of opinions on the profession.

Normalised to take the differing sizes of the corpora into account, the TS and M\&G scores for sex worker* terms are nearly identical at 96 and 98, respectively. However, a vast difference in the use of prostitute* forms is evident, with scores of 170 and 27, respectively. This means that TS uses prostitute* in $64 \%$ of instances, while the M\&G uses sex worker* $78 \%$ of the time. Thus, while themes associated with both sets of terms are considered in our analysis, discourses linked to the prostitute* forms in TS, in particular, should be acknowledged as dominating that data set, and sex worker* the M\&G.

\subsection{Sex work as a moral issue}

Both publications invoke the notion of sex work as morally problematic, and use this as an argument against the occupation, but they vary in terms of their objection to it.

In the TS data, sex work is presented as morally wrong in itself, which encompasses the sex workers and the practice. This is realised as an anti-decriminalisation discourse, most evident when prostitute* is used. The following concordance lines show a metaphorical "war on prostitution" which is concerned with "rescuing" innocent girls from a false choice:

It also encourages people to wage war against prostitution.

it says "driving prostitutes out of a neighbourhood permanently requires more rescued NN and other girls from a life of prostitution. ANOTHER CHANCE Mkhize yesterday, calling for a clampdown on prostitution. Calling themselves saying it would crack down on prostitution in the city and would arrest sex workers

Although the sex worker and the practice of sex work are stigmatised, there is a lesser degree of disapprobation for the client of the sex worker, whose criminal involvement in the transaction is described almost playfully as an anticipated misdemeanour.

Even the 2010 soccer fans, in whose anticipation elaborate plans are afoot to cater for their sexual misdemeanours, would hate prostitution as an occupation for family members.

Decriminalisation advocacy group, SWEAT, is represented as promoting immoral interests: Evil lurks behind sex workers grouping. Sex Workers Education and Advocacy

Task Force must not force its lack of morals on South Africa. 
Although SWEAT and its aims are mentioned, they are done so with a negative evaluation: they are judged in terms of "morality" and are found wanting, reiterating to the readers that this is an important consideration. This illustrates that it is not only whether or not certain voices are found in media texts, but also how the discourses they espouse are framed, that contributes to the ideological work done by the publication. The TS articles reflect a moral/cultural/religious view, dominant in much of Africa, which underlies the criminal status of sex work in most countries on the continent, and raises, according to SWEAT, issues of human rights.

To a limited extent, the M\&G also aligns itself with (often) religious, moralistic arguments against sex work. However, instead of basing these arguments on the assumption that sex work is "sinful" behaviour (as in TS), here the argument against sex work is that it involves the sale of male access to sex with women's bodies, which is represented as wrong in that it infringes women's rights ${ }^{8}$, and is linked to other criminal activities.

Frequent collocates of sex include sell and buy: sell* collocates with sex particularly frequently $\left(8, \mathrm{MI} 7.14^{9}\right)$, and $b u y^{*}$ with sex less frequently but nonetheless statistically significantly $(2$, MI 7.14). A concordance analysis shows that the concepts of 'selling sex' and 'buying sex' are mostly centred on the degree of optionality a woman has to sell sex.

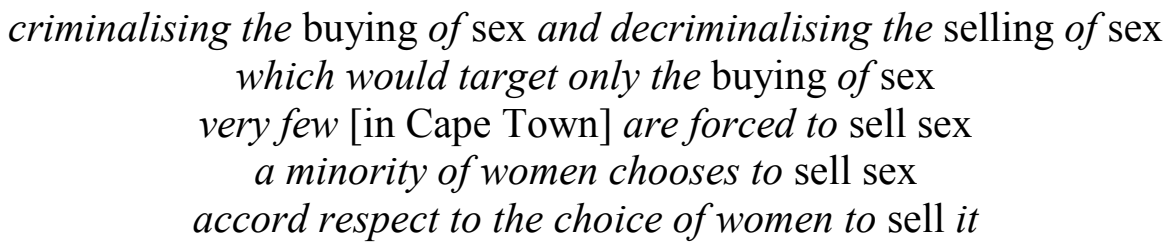

The act of buying ( 3 tokens) is discussed less than that of selling (12 tokens), which implies that sex work is still being constructed as a one-sided transaction. The other actors in the sex industry are evident in the collocates for client* - madams (MI 10.42), pimps (MI 9.42) and brothel [owners] (MI 7.84) - as are transactional words like choosing (2, MI 9.84), negotiate (2, MI 8.84), charge (MI 7.84), amount (MI 9.42) and pay (MI 6.67). While not individually frequent, together these collocates invoke the notion of a business transaction without explicitly using the word "buy". The M\&G explicitly discusses the benefits of criminalising buying and decriminalising selling in its coverage in terms of human rights (cf. section 5.3). Thus sex work is represented as a site of human rights abuses, chiefly of the sex workers themselves, and these constitute a moral problem, rather than the practice of sex work being seen as immoral, as is the case in the TS data.

\footnotetext{
${ }^{8}$ The high frequency for $w^{*}{ }^{*} n$, as compared to $m^{*} n$, suggests that women is used as a synonym for sex workers (thereby eliding the minority of male sex workers) and, consequently, that there is greater focus on female sex workers than men and clients in the $\mathrm{M} \& \mathrm{G}$ data. This trend is strengthened by the preoccupation in the human rights discourse, with police rather than clients as perpetrators; sex workers, their actions and abuses are highlighted, while clients and their behaviour are largely obscured.

${ }^{9}$ These are statistics for frequency and collocational strength, respectively.
} 


\subsection{Sex work as associated with crime}

Sex work is sometimes thought to encourage other criminal activities such as drug dealing, theft and human trafficking, as illustrated by the following quote by Safety and Security Councillor Smith $(M \& G)$ :

\section{The city has found a link between sex work and an increase in other criminal activities in an area.}

The M\&G data confirm this link in that words and phrases with negative expressive value tend to surround the word prostitution, and, to a lesser extent, sex work* prostitut* collocates with trafficking (MI 3.61), forced (MI 6.12), gangs (MI 7.93), illegal (MI 6.93), minors (MI 7.93) and underage (MI 8.93), while sex work* collocates with crime (MI 4.33) and trafficked (MI 5.23).

The collocational relationship between sex work and crime in the M\&G is supported by one syndicated article in particular, which provides little analysis or outside opinion and mostly quotes the $\mathrm{ACDP}^{10}$. However, the article uses sex work even in the headline, ACDP: Legalising sex work will legitimise crime, whereas all quotes from the ACDP speaker use the more stigmatised term prostitution. This, and the foregrounding of "ACDP" in the headline, could be a technique used by the news syndicate and the $M \& G$ to separate the respective stances, thereby distancing themselves from this more judgemental view.

In the TS data, prostitut* is strongly linked to crime, while sex work* is not. The collocates of prostitution often relate to crime and deviance, with humiliation (MI 8.56), (paid) rape (both MI 7.56), trafficking (MI 5.68) and child abuse (child MI 5.89) among the top ten collocations with the word. By creating a link in the mind of the reader between the sexual acts of prostitution (as opposed to sex work) and crime and deviance, the journalist primes the reader to expect the concepts to cooccur. Prostitution is therefore constructed as a dangerous context for sexual activity, as well as being linked to moral shame and social disapproval, as discussed above.

The collocations with prostitute also reflect the criminal aspects of the work with victim (MI 8.46) and murder (MI 7.87), while the majority of the terms which collocate with prostitutes reiterate this connection, including arrested (MI 7.58) and gang (MI 7.87). Three of the top ten collocates, unsuspecting, lure and motorists (MI 8.87, 8.46 and 8.24, respectively), refer to an apparently common practice of prostitutes being forced to lure unsuspecting motorists for the purpose of stealing from them, once again deepening the connection between prostitution and crime, and highlighting the apparent powerlessness of sex workers.

Collocates of sex workers relating to crime in TS, however, are not very common, forming only a minor association, and include protection and criminals (MI 4.6 and 4.5, respectively).

\subsection{Sex work as a human rights issue}

The treatment and positioning of sex workers is overwhelmingly seen as human rights abuse in the M\&G data, while about a third of the TS articles represent sex work this way. In TS, these articles typically use the terms sex work and sex worker $(s)$ in preference to prostitution and

\footnotetext{
${ }^{10}$ The African Christian Democratic Party: a South African political party with an explicitly Christian stance.
} 
prostitute(s), with almost no exceptions. By this we mean that there are no articles which both use the prostitut* forms predominantly and advocate the promotion of the human rights of sex workers. There are, however, a few articles which support this view while using prostitut* forms occasionally, typically in direct quotes from sources. The almost exclusive use of sex work forms in the M\&G data, then, shows how the choice of this term indexes a human rights position ideologically, given the publication's more or less exclusively pro-decriminalisation stance. In the following sections, we consider two key ways in which sex work is represented as a human rights issue: advocacy for the improvement of conditions, which includes calls for decrimininalisation, and the recognition of sex work as an occupation.

\subsubsection{Advocacy and decriminalisation efforts}

Advocacy for better conditions and calls for decriminalisation are often intertwined in both data sets, although they are represented rather differently. While the M\&G data reveal a stance that is unambiguously pro-decriminalisation, the TS corpus varies. In TS, both advocacy and decriminalisation are represented positively, or at least neutrally, in the collocates for sex work (presented in Table 2), which cluster together to reveal a preoccupation with human rights. Types such as thorny, question, illegal, law, right, decriminalised and decriminalisation reflect a concern with the public discussion about the legal status of sex work, now and in the future, couched in the context of (human) rights.

Table 2: TS collocations of sex work: span 4L - 4R (MI score)

\begin{tabular}{|l|l|l|l|}
\hline \multicolumn{3}{|c|}{ sex work } \\
\hline Rank & Freq. & Type & MI \\
\hline 1 & 2 & thorny & 6.37 \\
\hline 2 & 35 & work & 5.55 \\
\hline 3 & 2 & question & 5.37 \\
\hline 4 & 2 & decriminalised & 5.37 \\
\hline 5 & 2 & calls & 5.37 \\
\hline 6 & 3 & increase & 5.15 \\
\hline 8 & 5 & decriminalisation & 4.99 \\
\hline 9 & 2 & union & 4.37 \\
\hline 10 & 2 & illegal & 4.05 \\
\hline 11 & 3 & law & 3.87 \\
\hline 12 & 2 & right & 3.67 \\
\hline
\end{tabular}

This concern with group rights is further reflected in the concordance lines for sex work, of which nearly two-thirds (21 out of 35 ) refer to the legal status of sex work in general, or decriminalisation specifically, as in the following:

to the debate on decriminalising sex work ahead of the tournament Advocacy Task-force. Sex work is illegal in most African countries. finally entreat him to decree "sex work" into law as the president of calls for decriminalisation of sex work, as it recognises that sex for the decriminalisation for sex work. Barnett, who played an 
Of the TS collocates of sex worker, education (MI 5.18, rank 4), advocacy (MI 4.98, rank 6) and appeal (MI 3.37, rank 9) refer to the efforts of various civic organisations to address the legal status of the profession. Many legal terms also collocate with the plural form sex workers, as may be seen in Table 3, such as unlawfully, relief (both MI 6.37) and arresting (MI 5.05), while others relate more to advocacy, such as alliance, advocacy, protect, protection, ministry, free, call and justice. The types decriminalise, human and rights (the latter two most commonly occurring together as a cluster) span both domains, showing the preoccupation in these articles with calls for the decriminalisation of sex work in the context of legal advocacy. The fact that unlawfully, in the context of sex workers, refers to the unlawful arrest of the workers, rather than referring to what they do, shows how these articles take the part of sex workers and represent them sympathetically.

Table 3: TS collocations of sex workers: span 4L - 4R (MI score)

\begin{tabular}{|l|l|l|l|}
\hline \multicolumn{4}{|c|}{ sex workers } \\
\hline Rank & Freq. & Type & MI \\
\hline 4 & 2 & unlawfully & 6.37 \\
\hline 5 & 2 & relief & 6.37 \\
\hline 6 & 2 & ministry & 6.37 \\
\hline 7 & 2 & decriminalise & 6.37 \\
\hline 12 & 7 & education & 5.18 \\
\hline 13 & 2 & arresting & 5.05 \\
\hline 14 & 2 & alliance & 5.05 \\
\hline 15 & 8 & advocacy & 5.0 \\
\hline 17 & 2 & protect & 4.79 \\
\hline 18 & 2 & free & 4.79 \\
\hline 24 & 2 & call & 4.56 \\
\hline 25 & 3 & protection & 4.6 \\
\hline 26 & 3 & criminals & 4.5 \\
\hline 27 & 2 & justice & 4.37 \\
\hline 35 & 3 & human & 3.87 \\
\hline 41 & 3 & clients & 3.56 \\
\hline 42 & 3 & rights & 3.43 \\
\hline
\end{tabular}

In contrast, advocacy and education rank relatively low with the prostitut* terms in TS, with only three concordance lines. More frequent are references to the legal status of the occupation (ranked second for prostitution), but the emphasis here is on the illegality of the work and arrests that have taken place in that context. Calls for decriminalisation are either presented as problematic or rejected outright.

Prostitution is illegal in South Africa, and prostitutes and their clients can be charged Mdunge said the men and the prostitutes were arrested on the spot. The owner of the Tlali said cases involving prostitution had not been easy to prosecute. "There must for them to be charged with the crime of prostitution." Smith conceded that officers were yesterday divided over a call to legalise prostitution brought by the Police madams and exploit others? Don't legalise prostitution, but rescue the women 
The M\&G data construct a pro-decriminalisation discourse by quoting extensively from interviews with sex workers as well as the opinions of advocacy organisations like SWEAT and Sisonke ${ }^{11}$, contrary to SWEAT's (2010) findings that sex workers are typically not given enough of a voice in news media. To illustrate the inclusion of their voices, Figure 1 below shows that the token she said appears 23 times, and $78.3 \%$ of those instances refer to sex workers ${ }^{12}$. The pie chart also shows that SWEAT's spokesperson is the most quoted woman who is not a sex worker.

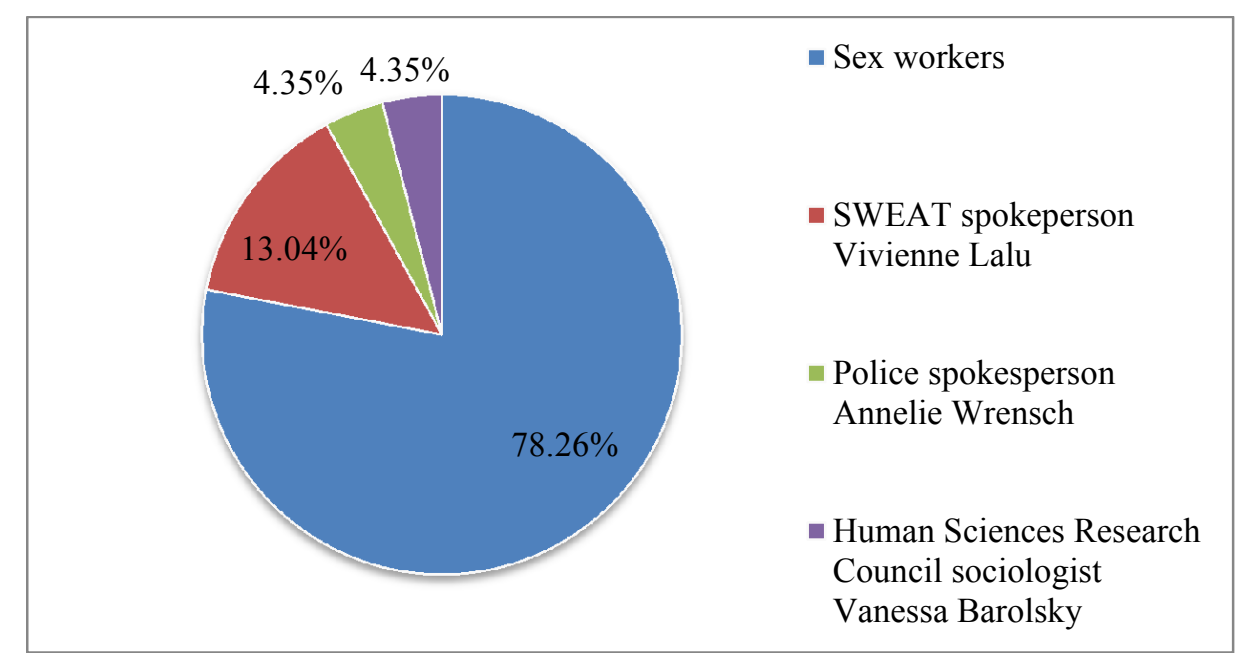

Figure 1. Referents of the cluster she said

By drawing on sex workers and their advocates as experts, the rights of sex workers are legitimised, and calls for a change in their legal status are positioned as the common-sense view. In addition, sex work is often framed as an occupation and as a rational choice for the povertystricken.

\subsubsection{Sex work as an occupation}

The representation of sex work as an occupation is relatively common amongst the TS concordance lines, especially in those for sex work itself where it ranks second. Discussion of a case before the appeal court regarding whether a dispute between a "sex worker" and her employer could be heard by the Commission for Conciliation, Mediation and Arbitration (CCMA, a labour dispute resolution body) accounts for most of these (11/17), as the issue centred on whether the contracts of sex workers, while unlawful, are governed by labour law. The content reports a legal decision which allows sex workers to ask for remedy for labourrelated injustices, but the use of scare quotes belies something of an incredulous response to this event by the writers.

ministries could be petitioned to register "sex work" as a career option. If morality is with gentle aloofness. Were "sex work" to be deemed to be a legitimate occupation, the CCMA could entertain a claim by a "sex worker" whose services at a massage unlawful duties. It further held that "sex workers" could not be entitled to relief

\footnotetext{
${ }^{11}$ Sisonke is SWEAT's Johannesburg counterpart.

12 There are no male sex workers quoted, which entrenches a common myth that all sex workers are women. The token male prostitute only occurs once and this qualification constructs this as the exception to the norm.
} 
fight for their rights "I hope the girls (sex workers) will now stand up for themselves decriminalisation would ensure that sex workers were regulated and that tax

This theme ranked low for prostitution, and not at all in its related terms, with only two lines, both of which were negative towards the view:

\section{labour under the misconception that prostitution is "work", will be}

However, the view of sex work as employment is strongly represented in the M\&G data, especially as it quotes an "employment law specialist" on the Labour Appeals Court (LAC) ruling against a brothel for discriminatory retrenchment mentioned above. The extract below indicates sex workers' reasons for entering the sex industry, emphasising their agency and choice in the matter:

Sex workers in Limpopo also called on the police and society to respect sex workers' means of survival, and recognise sex work as a form of employment.

The phrases sex workers' means of survival and sex work is a rational choice for survival (2) support this advocacy view. In the concordance line below, SWEAT advocates decriminalisation for pragmatic reasons such as decreasing labour exploitation:

\section{They would be less vulnerable to exploitation," said Harper.}

However, sex work, while recognised as employment in the $\mathrm{M} \& \mathrm{G}$, is classed as second-rate employment almost across the board - by sex workers, advocates and feminists alike. The token employment collocates with kinds (MI 9.42), form (MI 8.84) and line (MI 9.42), which indicates a preoccupation with sex work as a type of employment. This sets up a relationship of hyponymy within the classification scheme of work. The social values attached to different levels of work, in turn, set up a powerful parallel hierarchy of different kinds of women and the various social values attached to them, with SWEAT spokespeople quoted as saying they do not promote sex work as a long-term option.

The representation of sex worker advocacy in the M\&G constructs sex workers as people to empathise and engage with - an improvement on the print media investigated by SWEAT (2010). The M\&G reports on several events where the sex workers' welfare is the focus of the story, although the fact that the controversy of such stories boosts sales might be responsible for this, rather than justice. Furthermore, as indicated above, the M\&G data sometimes represent sex work as a type of employment, which promotes a more positive view of sex work, even though they acknowledge that advocates do not view sex work as a desirable long-term option.

\subsection{Police harassment}

The perceived harassment of sex workers by police is the most prominent theme in the TS concordance lines for both prostitutes and sex workers. In the prostitutes lines, sex workers are represented as the regular victims of police harassment, but also as problematic for the police, as the final line in the following extract from the concordance shows: 
for a long time. To them [police] prostitutes are fair game to be harassed and to do as they [police] please with prostitutes, as though children of a lesser god, an application by the city's prostitutes to stop the police from unlawfully arresting World Cup. She singles out prostitutes as posing a "really tough job" for the police.

Over half of the sex workers lines in the TS data refer to differential police treatment according to race. Here, the sex workers are said to be targeted as a group because of their occupation, but more particularly because they are seen as members of a particular racial group.

vice squad is unfairly targeting black sex workers, while leaving white sex workers only blacks are harassed' White sex workers not hassled, say prostitutes of turning a blind eye to white sex workers who dominate the city's escort agencies.

Two collocates of sex workers, leaving (MI 7.37) and target (MI 6.0), refer to perceived police harassment of black sex workers in particular. Both of these are congruent with a fairly abstract discourse of protection and decriminalisation, one which is concerned with the human rights of sex workers in general.

In the $M \& G$ data, the police were represented as the most frequent perpetrators of human rights abuses (35 tokens), while two other groups of abusers occurred far less often: clients (3) and employers, the latter in the form of hotel manager* (2).

Amongst the strongest collocates for police ${ }^{13}$ in the $M \& G$ are some words that would be expected to surround this type, given the job description: magistrates, Minister, station, van, some personal names, titles such as Superintendent and Captain, and appropriate actions such as arresting, intervention and identified (all MI > 7). However, brutality (MI 7.57), harassing (MI 7.57), indifferent (MI 7.57), repeatedly (MI 7.57), targeting (MI 7.57), targets (MI 7.57) and torture (MI 7.57) cluster together to form an aggregate of meaning which suggests activities on the part of the police that are less expected and decidedly negative. Individually, these words are not very frequent but the fact that they regularly occur close to police, more than anywhere else, and that they form a cluster of related meanings, contributes to a negative discourse prosody of the police as perpetrators of human rights abuses. Both harassing and targets/targeting relate to the frequent portrayal of the police repeatedly arresting sex workers when there is insufficient evidence for conviction. These two terms as well as repeatedly show strong negative expressive value, revealing a disapproval of police involvement in human rights abuses in the $M \& G$ data. The presence of lexemes like brutality and torture signals a particularly sinister suggestion that law enforcement in South Africa is violent and oppressive towards sex workers.

The police concordance lines in the M\&G show the police represented as perpetrators of human rights violations, specifically robbery, rape, physical abuse, harassment and bribery. The most frequent violation is harassment, referenced 10 times in the data, for example:

We are targets for them [police] on the road police were arresting them merely to harass and intimidate them.

The police are also harassing us.

${ }^{13}$ Here the span is $1 \mathrm{R}-4 \mathrm{R}$ to capture the verbs predicated of the type police as subject. 
This frequency is partly attributed to a widely-reported court interdict that stopped police from arresting sex workers because the National Prosecuting Authority kept failing to prosecute them. The M\&G data emphasise that the Cape High Court believed that these arrests were a form of unnecessary harassment against sex workers.

The M\&G concordance lines also show an emphasis on physical violence by police towards sex workers. Firstly, this is evident in the words torture, abuse and brutality. These examples have high negative expressive value that reinforces the horror of crime-fighting police officers committing these crimes. While clients and employers are also seen as responsible for physical abuses, the M\&G data almost exclusively focus on the police.

Secondly, violence in the form of rape and sexual abuse appears six times in the M\&G concordance lines. In addition, the quoted lines below suggest that both rape by police and the police's reluctance to open rape cases for sex workers reflect the dangerous myth (also found in the TS data) that sex workers, because they sell sex, are not like other women and "cannot" be raped.

Nor much support from the police, as "you people cannot be raped" and "you got what you deserved"

The use of scare quotes in this line indicates in this case a distancing mechanism whereby the newspaper rejects being associated with this view of rape and of sex work.

Police corruption in the form of robbery and demanding bribes is reflected in six M\&G lines, and can be seen in the following phrases: take my money, give our money to cops, corrupt policemen and robbed. Such corruption often accompanies other abuses, as in the phrase bribery and rape. This link portrays rape as the punishment for not submitting to male authority and coercion. This becomes more explicit in the following lines:

"The police are also harassing us. It's either they want a quickie or you are arrested and forced to pay a spot fine."

the police approach prostitutes on the street and ask for a "cold drink", which translates into a bribe. "If we don't pay they take us to the cells and they rape the girls in there."

The outrage against abuses, so marked in the $M \& G$ data, emphasises the human rights dimension rather than the lower position of women in society - the latter being the root cause of sex worker abuse. The sex workers are seen to be challenging their abusers to a certain extent: human rights collocates with various phrases of defiance such as sex workers protest, no longer be silenced and the fight for. More generally though, the label of "human rights abuse" constructs the sex workers as victims without agency, and focus is placed upon the police who are constructed as their main abusers. Significantly, rights collocates with prostitute* only once but with sex work* (MI 5.08) 13 times, indicating a much stronger link between the use of the term sex work$^{*}$ and human rights discourses.

The overarching theme in both corpora is that rather than safeguarding these citizens, the South African police force endangers them. While TS emphasises the targeting of black sex workers by police, reflecting the salience of race in South African society, the M\&G potentially engages 
public sympathy by constructing all sex workers as human beings who are victims of unacceptable abuses of power, eliding issues of race.

\subsection{Danger and damage to the individual}

Sex workers are frequently represented in the TS data as marginalised and victimised. Part of this is linked to the group being seen as being in danger, although this is a less frequent theme than individual vulnerability. The sex workers thus marginalised and exploited are positioned as having their basic rights reduced, and the practical expression of this is being in danger and unable to access help from the police and health services.

homeless people, newspaper vendors, sex workers or people forced to survive on the leave real criminals untouched, while victimising sex workers who are already among human rights. Yet his statement means that sex workers should be denied these rights. According to the UN, sex workers in many settings are socially marginalised gangsterism, robberies and taking advantage of sex workers. A Johannesburg worker of sex work, as it recognises that sex workers face barriers in accessing prevention

The individual sex worker's safety is at issue, as is the question of choice and consent. These views come to the fore in the articles which use prostitut* as their dominant term. In the sex worker lines, the most frequent use is to point out a specific person, with varying degrees of anonymity, usually used as a case study to personalise a generalised argument. We do not see this as a TS theme as such, but rather as a strategy to emphasise the individuals involved in a practice which tends to be represented in these articles in a fairly abstract and theoretical way. Danger for sex worker* is connected with the marginalisation and victimisation of the group, but for both prostitution and prostitute, the association with danger as an individual is the most prominent theme in the concordance lines, which show abortion, physical damage and even murder amongst the dangers sex workers face.

2533. Residents fume over murder of 'prostitute' Residents of Newcastle in the man linked to the murder of a suspected prostitute is granted bail. The 22-yearprostitution intrinsically involves harm for the prostitute. Sexual acts in prostitution the fact that what occurs in prostitution, the bodily and psychological violations, are morally wrong. The protesters said prostitution led to drug abuse, increased abortion trafficking associated with prostitution intrinsically involves harm for the prostitute.

Another danger evident in the collocates of prostitutes in TS is rape, particularly the justification of rape via claims of prostitution, which is partly responsible for strong collocation relationships with the terms victim and gang. A number of articles were excluded from the corpus because they were not about sex work as such, but had come up in the search due to their use of the word prostitute. In each excluded article, the accused parties in rape cases had claimed in their defence that they thought the victim was a sex worker, referring to her as a prostitute, which was argued to render her "unrapeable". Despite removing articles where there was no other discussion of sex work, the use of claimed prostitution as a "justification" for rape is still reflected in the remaining data, as in the following extracts from the concordance lines for prostitute: 


\section{gang rapists' claim victim is a prostitute \\ denied claims by one of the accused that the victim was a prostitute}

The assumption that sex which may be sold cannot be stolen reveals a startling commodification of women's bodies, which is inconsistent with the notion of sex work as work, and suggests an attitude of patriarchal entitlement amongst the accused parties in these cases.

The view of sex work as "paid rape" supports this interpretation, with rape being intrinsically harmful whether paid for or not. This emerges as a theme in the TS prostitution lines:

affection or mutual respect involved. Prostitution can therefore be seen as paid rape. Nomfundo Ndlovu is thankful for being saved. Prostitution is paid rape. In a call

In the M\&G, collocates for client* cluster together to form a rather different discourse prosody concerned with risks to client safety and anonymity: scared (MI 9.42), flee (MI 10.42), photographing (MI 10.42) and infection (2, MI 10.42). The concordance lines below show that what clients are scared of is losing their anonymity.

\section{When the flashes go off, clients flee. They're most concerned about anonymity and they don't want their wives to find out \\ When a client is busy with a girl, the cops come and tell the client 'Come with us to the bank or we'll tell your wife'}

Since buying sex is only recently illegal in South Africa, clients typically do not fear criminal charges but only exposure, and so sometimes are manipulated by police and various moral watchdog groups. The M\&G distances itself from these groups through the use of scare quotes in reporting on their activities.

In comparison to the police's actions, any threat to sex workers from clients has been largely elided. Given the skewed demographics in the sex industry, the semi-obscuration of clients' involvement and possible abuses are a form of patriarchal dominance since men's sexual nature is portrayed as excusing their sexually deviant behaviour.

\section{Comparison of the M\&G and TS data}

As we have outlined above, the $M \& G$ corpus is fairly homogenous with respect to how sex work is represented. For the most part, in the M\&G corpus, sex work is associated with advocacy work and the debate regarding the legal status of the occupation as well as its possible recognition as a profession. Where criminality is a focus, contrary to expectations, the sex workers are the victims and the police the perpetrators of the crimes. This is in direct opposition to the historically dominant discourse which positions the police as morally good and those who break the law as bad. The overall discourse is one of support for (if not approval of) sex workers, and the tone is generally intellectual, resulting in a relatively abstract, liberal stance and the almost complete use of the lemma sex work* as opposed to prostitut*.

In the TS corpus, the choice of which term to use - either sex work* or prostitut* - indexes the discourse invoked in the particular article. The lemma sex work* is used in the context of a progressive ideology of human rights, similar to that found in the M\&G data. Unlike the M\&G 
data, however, the police are not represented as the agents associated with the crimes mentioned. In fact, crime is revealed as an almost expected contextual feature of sex work, a stance particularly clear in the collocates with prostitut ${ }^{*}$. This term is associated with individual conditions and experiences, with crimes against sex workers and the dangerous nature of their work, and very frequently with disapproval for various reasons. Thus, although the question of decriminalisation is raised in the TS data, the common-sense subject positions of police $=$ good and sex worker $=$ bad are not overturned, and prostitutes in particular retains a strong negative evaluation. Significantly, the use of prostitut* in the TS corpus, in preference to sex work* (in a ratio of approximately $2: 1$ ), means that the associations with crime and disapproval are much more dominant than the legal, advocacy issues, and the TS texts in general emphasise discourses of deviance over human rights.

The contrasts found in each corpus are further reflected in the comparative measures available via keywords. The keywords for each sub-corpus are shown in Table 4. In this table, those words which are especially characteristic of the M\&G corpus, relative to the TS corpus, are shown in the left three columns, together with the Log Likelihood (LL) score ${ }^{14}$, which provides a measure of the statistical significance of their "keyness", while those for the TS corpus are on the right-hand side of the table.

Table 4: Keywords: M\&G versus TS

\begin{tabular}{|l|l|l|l|l|l|l|l|}
\hline \multicolumn{4}{|c|}{ M\&G Top 10 Keywords } & \multicolumn{4}{c|}{ TS Top 10 Keywords } \\
\hline Rank & Freq. & LL & Type & Rank & Freq. & LL & Type \\
\hline 1 & 70 & 23.729 & women & 1 & 45 & 27.613 & men \\
\hline 2 & 11 & 19.336 & players & 2 & 22 & 23.609 & house \\
\hline 3 & 14 & 18.334 & angels & 3 & 22 & 23.609 & white \\
\hline 4 & 14 & 18.334 & guardian & 4 & 16 & 17.17 & addiction \\
\hline 5 & 10 & 17.578 & feminists & 5 & 31 & 15.421 & HIV \\
\hline 6 & 10 & 17.578 & report & 6 & 50 & 15.421 & sexual \\
\hline 7 & 10 & 17.578 & Sweden & 7 & 23 & 14.259 & man \\
\hline 8 & 38 & 17.018 & law & 8 & 13 & 13.951 & yesterday \\
\hline 9 & 9 & 15.82 & feminist & 9 & 16 & 11.321 & black \\
\hline 10 & 16 & 12.401 & commission & 10 & 9 & 9.658 & well \\
\hline
\end{tabular}

The intellectual/legal emphasis in the M\&G is evident in the keywords: the types feminists, report, Sweden, law, feminist and commission are all significantly more frequent in the M\&G than in TS. This shows how sex work in the $M \& G$ is seen as a social, legal and intellectual issue, fairly abstract and argued in philosophical terms and via case studies, with a detectable antipathy towards moral as opposed to rational arguments. This last point is illustrated by the reportage on the Guardian Angels, both words which rank highly in the list of M\&G keywords. The Guardian Angels were a "moral"-based group dedicated to "clearing the streets" of prostitutes for the 2010 FIFA World Cup, and with whom SWEAT apparently took issue. The M\&G data refer to the person who began the organisation as a "high school drop out", characterise the group as "a private army" or group members as "paramilitaries", and their views and actions as "crimebusting actions" bordering on "vigilantism" - all represented in a negative light. In the following

\footnotetext{
${ }^{14}$ An LL score of more than 3 is deemed significant at a 95\% confidence level.
} 
extract, two groups established as authoritative in the $M \& G$ discourse are cited as expressing alarm and having fears about the programme.

\section{Both People Opposing Women Abuse (Powa) and the Sex Worker Education and Advocacy Task Force (Sweat) have expressed alarm about the city working with an organisation that they believe sees sex workers through a moral lens and not from a human rights perspective. There are also fears that the Guardian Angels programme will encourage vigilantism.}

By contrasting the Guardian Angels' response with SWEAT and POWA's activism, responses to sex work are constructed in these texts as binary: they are either morally-based (i.e. religious, with assumptions of judgement) or humanitarian, with the co-text carrying negative evaluation of the former. In the M\&G data, sex work is thus constructed largely as a human rights issue with the assumption that judgements about whether it is right or wrong are inappropriate.

In contrast, the TS list of keywords is more practical and less abstract, with more reference to specific acts in specific places at specific times. These words appear concerned with both individual and social effects of sex work, such as drug-taking, crime (as referred to above) and disease. One particularly noteworthy keyword is $H I V$, arguably one of the most serious of the dangers faced by sex workers. What is unusual about the very tight group of mostly content words which collocate with $H I V$ (see Table 5) is the high proportion of verbs amongst them which tend to refer to the transmission of the virus, including transmission itself, contracting, expose and spread. This reflects the main concern about HIV, of course, and also the unusual, almost agentive, qualities attributed to the virus, in that its movement from person to person is a significant fear. This preoccupation with HIV and its transmission, and the lack of a similar emphasis in the M\&G data, emphasizes TS's concerns with the problems affecting individual sex workers, as opposed to the broader social issues promoted by the M\&G.

Table 5: TS collocations of $H I V$ : span 4L - 4R (MI score)

\begin{tabular}{|l|l|l|l|}
\hline \multicolumn{4}{|c|}{$H I V$} \\
\hline Rank & Freq. & MI & Type \\
\hline 1 & 2 & 8.96 & transmission \\
\hline 2 & 2 & 8.96 & positive \\
\hline 3 & 2 & 8.96 & grannies \\
\hline 4 & 4 & 8.96 & contracting \\
\hline 5 & 2 & 8.38 & virus \\
\hline 6 & 2 & 8.38 & expose \\
\hline 7 & 2 & 7.96 & spread \\
\hline 8 & 2 & 7.96 & researcher \\
\hline 9 & 7 & 7.60 & aids \\
\hline 10 & 3 & 7.23 & am \\
\hline
\end{tabular}

The nouns referring to people in the keyword lists form an interesting contrast. In the M\&G data the most salient tokens are women, players, feminist and feminists while those in the TS corpus are men and man as well as two terms for racial classification, namely black and white. In part, the relative frequency of women in the $M \& G$ seems to be caused by the paper quoting spokespeople from various advocacy groups and reporting extensively on their activities; the 
names of these groups often include the word "women". Nearly half of the instances of feminist and 8 out of 10 of the instances of feminists come from one article which provides a nuanced discussion of the responses of various forms of feminism to sex work, juxtaposed with the imagined perspective of a sex worker. Despite this concentration in one text, it is nonetheless the case that the TS corpus does not contain a similar philosophical approach in any of its articles, let alone one with a feminist orientation.

A further significant difference is the four instances of the word "men" in the M\&G data, while TS has 45. Typical of its individualised approach, the TS use of this term is mostly to refer to specific things that men do to women, and over $25 \%$ of these instances are racialised or described in terms of nationality. Examples include African men, west African men, South African men, Black men and white men, and are in a way reminiscent of TS's distinction between black and white sex workers. In addition to this focus on men, then, the TS data reveal a preoccupation with race, while the absence of similar classification in the M\&G seems to be an expression of their somewhat sanitised post-apartheid stance.

The abstract/practical split is also reflected in the voices quoted in the articles: the M\&G tends to give high prominence to advocacy groups and researchers or lawyers, although they do include sex workers themselves, while TS uses a range of people, with less emphasis on abstract rational discussion and more on individual, emotional and moral responses.

\section{Conclusion}

We opened this article with two factors which were seen as contributing to the subordinate status of sex workers: their legal status under South African law, and the prevalence of negative representations in South African media. A legal change is beyond the purview of this article but it seems clear that not all media representations of sex workers revolve around the discourses of disease and immorality found by SWEAT (2010). Although some remnants of conservative views remain, notably in TS, the M\&G offers an almost unwavering pro-decriminalisation stance. Furthermore, while some liberal elements are evident in the TS data, congruent with their aims of change, the bulk of the reporting constructs discourses which act in a normative relationship to traditional views of sex work and sex workers as being in moral and physical danger.

While it could be argued that a multiplicity of views (such as is found in TS) is healthier in the media than a monolithic perspective, it is clear that while the TS representations tend to support and perpetuate existing dominant discourses in South African society, thereby preserving the status quo, the M\&G's ideological stance is, for the most part, transformative. This can be regarded as an attempt by the $M \& G$ to lead its readership out of existing paradigms concerning sex and human rights. Instead of placing women who engage in sex work especially low on the ladder of acceptable femininity - itself subordinate to masculinity - the publication positions them as part of the larger group of human beings, and, as such, as fully deserving of human rights.

The implications of these findings are both encouraging and discouraging, from the point of view of those concerned with justice and the improvement of the lot of women. While the work of symbolic elites such as the journalists of the Mail and Guardian is far more positive than that researched by SWEAT (2010), and has the potential to support social change towards equality, the coverage in The Sowetan - with its far broader reach in terms of readership - 
reveals that South African society, as reflected and positioned in the TS data, still clings with steadfast tenacity to views of women in general, and sex workers in particular, which are firmly rooted in patriarchy. Ultimately, this reproduces assumptions and subject positions which further marginalise and disempower those whose access to agency is already precarious and circumscribed.

\section{References}

AMPS. 2012. All Media Products Study survey. Available online: http://www.saarf.co.za/ampsreadership/2012/AMPS\%20DEC\%202012-\%20READERSHIP\%20SUMMARYwith\%20Non\%20Pay-for\%20SAARF.pdf (Accessed 4 November 2013).

Anthony, L. 2011. AntConc (Version 3.2.2) [Computer Software]. Tokyo, Japan: Waseda University. Available online: http://www.antlab.sci.waseda.ac.jp/ (12 August 2015).

Baker, P., C. Gabrielatos, M. Khosravinik, M. Krzyzanowski, T. McEnery and R. Wodak. 2008. A useful methodological synergy? Combining critical discourse analysis and corpus linguistics to examine discourses of refugees and asylum seekers in the UK press. Discourse and Society 19(3): 273-306.

Baker, P. 2004. Querying keywords: Questions of difference, frequency and sense in keyword analysis. Journal of English Linguistics 32(4): 346-359.

Baker, P. 2006. Using corpora in discourse analysis. London and New York: Continuum.

Baker, P. 2008. Sexed texts. London, Oakville: Equinox.

Barrington, J. 2008. Shapeshifting: Prostitution and the Problem of Harm - A Discourse Analysis of Media Reportage of Prostitution Law Reform in New Zealand in 2003. Unpublished MA thesis, Auckland University of Technology, New Zealand. Available online: http://www.rapereliefshelter.bc.ca/sites/default/files/imce/Shapeshifting Barrington.pdf

(Accessed 23 July 2015).

Coy, M., J. Wakeling and M. Garner. 2011. Selling sex sells: Representations of prostitution and the sex industry in sexualised popular culture as symbolic violence. Women's Studies International Forum 34(5): 441-448.

Crymble, L. 2011. Textual Representations of Migrants and the Process of Migration in Selected South African Media: A Combined Critical Discourse Analysis and Corpus Linguistics Study. Unpublished MA thesis: Rhodes University, Grahamstown, South Africa. Available online: http://contentpro.seals.ac.za/iii/cpro/DigitalItemPdfViewerPage.external?id=20964106991430 35\&itemId $=1002624 \&$ lang $=$ eng \& file $=\% 2$ Fiii $\% 2 F c p r o \% 2 F a p p \% 3 F i d \% 3 D 209641069914303$ 5\%26itemId\%3D1002624\%26lang\%3Deng\%26nopassword\%3Dtrue $\% 26$ service $\% 3$ Dblob\%2 $\underline{6 \text { suite } \% 3 D d e f \# l o c a l e=e n g \& g r i d V i e w=t r u e ~(A c c e s s e d ~ o n l i n e ~} 23$ July 2015).

Fairclough, N. 2001. Language and power. London: Longman. 
Gabrielatos, C. and P. Baker. 2008. Fleeing, sneaking, flooding: A corpus analysis of discursive constructions of refugees and asylum seekers in the UK press, 1996-2005. Journal of English Linguistics 36(5): 5-38.

Grjebine, L. (Ed.) 1987. Reporting on prostitution: The media, women and prostitution in India, Malaysia and the Philippines. Paris: UNESCO. Available online: http://unesdoc.unesco.org/images/0007/000772/077215eo.pdf (Accessed 23 July 2015).

Hallgrimsdottir, H.K., R. Phillips and C. Benoit. 2006. Fallen women and rescued girls: Social stigma and media narratives of the sex industry in Victoria, B.C., from 1980 to 2005. Canadian Review of Sociology 43(3): 265-280.

Hardt-Mautner, G. 1995. 'Only connect': Critical discourse analysis and corpus linguistics. Unit for Computer Research on the English Language Technical Papers 6. Lancaster, UK: University Centre for Computer Corpus Research on Language, Lancaster University.

Lazar, M. 2005. Feminist critical discourse analysis: Gender, power and ideology in discourse. New York: Palgrave.

Mail \& Guardian Online. 2011a. About us. Available online: http://mg.co.za/page/about-us/ (Accessed 16 August 2011).

Mail \& Guardian Online. 2011b. Multimedia Rate Card 2011. Available online: http://mg.co.za/uploads/MG_online_rate_card.pdf (Accessed 1 October 2011).

Mautner, G. 2009. Checks and balances: How corpus linguistics can contribute to CDA. In R. Wodak and M. Meyer (Eds.) Methods of critical discourse analysis. London: Sage. pp. 122-143.

McEnery, T. and A. Wilson. 2001. Corpus linguistics. Edinburgh: Edinburgh University Press.

McLaughlin, L. 1991. Discourses of prostitution/discourses of sexuality. Critical Studies in Media Communication 8(3): 249-272.

O’Connell Davidson, J. 2002. The rights and wrongs of prostitution. Hypatia 17(2): 84-98.

O’Neill, M., R. Campbell, P. Hubbard, J. Pitcher and J. Scoular. 2008. Living with the Other: Street sex work, contingent communities and degrees of tolerance. Crime Media Culture 4(1): 73-93.

SAARF (South African Audience Research Foundation). 2009. LSM Presentation 2009. Available online: http://www.saarf.co.za/LSM/lsm-presentations.asp (Accessed 10 February 2015).

Scelles Foundation. 2009. The representation of prostitution in the media. Available online: http://www.fondationscelles.org/index.php?option=com content\&task=view\&id=26\&Itemid $=104 \&$ lang=en (Accessed 23 April 2011).

Sinclair, J. 2006. Aboutness 2 (manuscript). Italy: Tuscan Word Centre. 
Statistics South Africa 2010. Monthly earnings of South Africans, 2010. Pretoria, South Africa: Statistics South Africa. Available online: http://www.statssa.gov.za/publications/P02112/P021122010.pdf (Accessed 23 July 2015).

Sunderland, J. 2004. Gendered discourses. New York: Palgrave.

SWEAT (Sex Workers Education and Advocacy Taskforce). 2010. Sex sells: Monitoring reporting on the sex industry through a gender lens. Available online: http://www.sweat.org.za/docs/advocacy/monitoringSexIndustry.pdf (Accessed 14 April 2011).

Times Media. 2014. TMG Times Media Group overview Feb 2013 (presentation). Available online: $\quad$ http://www.timesmedia.co.za/wp-content/uploads/2011/05/TMG-Overview-Feb2013FINAL.pdf (Accessed 27 January 2014).

Wodak, R. and M. Meyer. 2009. Critical discourse analysis: History, agenda, theory, and methodology. In R. Wodak and M. Meyer (Eds.) Methods of critical discourse analysis. London: Sage. pp. 1-33. 